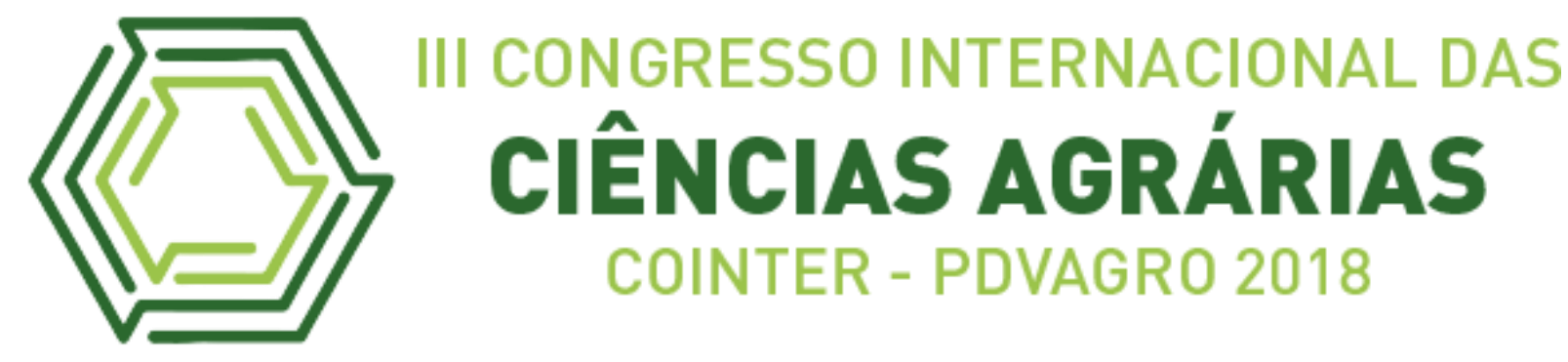

CONSERVAÇÃO PÓS-COLHEITA DE ROSAS

POST-HARVEST CONSERVATION OF ROSES

Rivaldo Vieira da Silva Filho ${ }^{1}$; Martha Carolina de Medeiros Cavalcante ${ }^{2}$; Renata Andrade Lima $^{3}$; Malena Luz de Almeida ${ }^{4}$; Paula Guimarães Pinheiro de Araújo ${ }^{5}$

Apresentação: Pôster

\title{
DOI: https://doi.org/10.31692/2526-7701.IIICOINTERPDVAGRO.2018.00394
}

\section{Introdução}

O setor da floricultura abrange o cultivo de flores e plantas ornamentais com variados fins. No Brasil, este setor, tem auxiliado de forma significativa na economia, uma vez que, é responsável por mais de 200 mil empregos diretos e indiretos (IBRAFLOR, 2015). Onde é considerado uma alternativa para quem busca investimento na agricultura, isto porque demanda pouca área e o ciclo de produção, dependendo da cultura, é curto (três meses), o que permite o giro rápido do capital. Pernambuco representa o segundo polo produtivo da região Nordeste, com produção em três regiões fisiográficas: Zona da Mata e Sertão - nas quais predomina a exploração da floricultura tropical - e o Agreste, onde se concentra o cultivo das espécies temperadas onde o clima, altitude e disponibilidade de água favorece, consideravelmente, a qualidade das flores. A produção destina-se ao abastecimento da própria região metropolitana do Recife e em menor proporção, para outros estados.

A produção de flores temperadas se encontra nos municípios de Barra de Guabiraba, Bonito, Camocim de São Félix, Chã Grande, Garanhuns e Gravatá. Este último, destaca-se em área cultivada e produtividade. Produtores buscam a tecnologia e inovação na produção, com instalação de estufas apropriadas e produção de novas cultivares, na tentativa de atender o consumidor com produtos de melhor qualidade. As principais flores temperadas produzidas no município de Gravatá são: crisântemo, rosa, gypsophila, carinho de mãe, gladíolo, gérbera, lisianthus, aster e tango. Entre as flores temperadas, a rosa é tradicionalmente apreciada,

\footnotetext{
${ }^{1}$ Bacharelado em Agronomia, IFPE-Campus Vitória, rivaldomapeli@gmail.com

${ }^{2}$ Bacharelado em Agronomia, IFPE-Campus Vitória, marthamedeiroscavalcanti@gmail.com

${ }^{3}$ Bacharelado em Agronomia, IFPE-Campus Vitória, renataprisco1@gmail.com

${ }^{4}$ Bacharelado em Agronomia, IFPE-Campus Vitória, malenaalmeida64@gmail.com

${ }^{5}$ Doutora e profo do Bacharelado em Agronomia, IFPE-Campus Vitória, paula.pinheiro@vitória.ifpe.edu.br
} 
representado, através dos tempos, símbolo de amor e beleza, além de ter servido como medicamento (água de rosas), alimento (chá, geleias, bebidas) e condecorações (PETRY, 2008). No Brasil, sabe-se que foram introduzidas pelos jesuítas entre 1560 e 1570, e o seu cultivo em jardins públicos iniciou-se em 1829, com Dom Pedro I (PETRY, 2008). É uma das principais flores de corte cultivadas no Brasil, concentrando 426 ha, seguidas por crisântemo com 234,5 ha, entre outras 70 espécies (JUNQUEIRA \& PEETZ, 2005).

O gênero Rosa L. é da família Rosácea, sendo um arbusto perene lenhoso, caracterizado por apresentar folhas caducas, compostas por cinco ou mais folíolos e estípulas presentes. O gênero rosa conta com cerca de duzentas espécies nativas hemisfério Norte, com ampla distribuição. Inúmeras espécies, cultivares e híbridos são produzidos para ornamentar parques e jardins, além de outras específicas para corte.

Entre os atributos de uma boa cultivar de rosa de corte está a boa conservação póscolheita, uma vez que esta flor é de curta durabilidade. A descoberta de soluções que possa proporcionar uma maior durabilidade é de interesse do produtor e do consumidor. Rosas da variedade "Grand gala" são amplamente cultivadas em Gravatá-PE, no entanto, os produtores têm tido problemas com a conservação pós-colheita dessas flores devido à sensibilidade que apresentam. Com isso, objetivaram-se com esse trabalho avaliar a durabilidade pós-colheita de rosas de corte variedade "Grand gala" com a utilização de soluções caseiras.

\section{Fundamentação Teórica}

Após a colheita, as rosas de corte têm um período de vida útil muito limitado que requer aplicação de técnicas para prolongar a durabilidade das flores, tal como o emprego de soluções conservantes (ALMEIDA, et al., 2009). Existem técnicas de conservação especificas que contribuem para manter a qualidade floral pós-colheita. Entre essas técnicas, a aplicação de uso de 'pulsing' com soluções de sacarose, produtos germicidas, para evitar a proliferação de microrganismos, produtos de ação anti-etileno e o armazenamento a baixas temperaturas são muito utilizadas (REIS, S. N. 2009). Segundo Finger et al. (2004) o controle da senescência das flores de corte é um processo que varia entre espécies e requer a otimização das relações hídricas, redução da abscisão ou murchamento das pétalas e flores, controle do crescimento dos microrganismos, e em muitos casos, o fornecimento de substratos respiratórios. 
Por serem muito requisitadas no mercado durante todo o ano, pesquisas voltadas a pós-colheita de rosa de corte, vem sendo realizadas em todo o Brasil. Em Gravatá-PE a variedade Grand Gala é a mais produzida e apresenta uma durabilidade média de oito dias, período considerado curto, uma vez que, a logística até o consumidor final é demorada. Com isso é necessário à descoberta de soluções que possa proporcionar uma maior durabilidade a essas flores.

\section{Metodologia}

O experimento foi realizado em setembro de 2018, na área de Produção de Mudas do Instituto Federal de Pernambuco, Campus Vitória de Santo Antão-PE. Trinta unidades de rosas da variedade "Grand gala” adicionadas nos tratamentos no $1^{\circ}$ dia de avaliação (figura 1) e uma rosa variedade "Grand gala" como demonstração de sua qualidade após sua chegada (figura 2), produzidas no Município de Gravatá-PE, foram colhidas e transportadas em água até o local destinado para o experimento. Um dia após a colheita, no laboratório, as hastes florais foram limpas (retirada às folhas), etiquetadas e padronizadas a $50 \mathrm{~cm}$. A temperatura média do ambiente em que se realizou o tratamento foi $25^{\circ} \mathrm{C}$ e a umidade relativa em torno de 58\%. O experimento foi composto por três tratamentos. T1 - água potável com $\mathrm{pH} 3 \%$, (testemunha). T2 - água destilada, açúcar cristal, suco de limão e vinagre; T3 - água destilada e açúcar cristal. As soluções foram feitas nas seguintes proporções: 1 litro de água, 2 colheres de chá de açúcar cristal, $50 \mathrm{ml}$ de suco de limão, 2 colheres de chá de vinagre.

Cada unidade experimental foi composta por um recipiente de plástico reciclável contendo $200 \mathrm{ml}$ da solução tratamento e dez hastes florais. A cada três dias as soluções foram trocadas e $2 \mathrm{~cm}$ do talo cortado. As hastes florais foram avaliadas qualitativamente a cada três dias, sendo atribuídas notas: nota 4 - haste floral (talo e botão floral) túrgida e sem sinais de escurecimento nas pétalas; nota 3 - perda de turgidez do talo e início de escurecimento na borda das pétalas; nota 2 - perda de turgidez do talo, e expansão do escurecimento nas pétalas; nota 1- descarte. Para a análise dos dados, gráficos foi gerados no programa Excel 2016 (figura 3).

\section{Resultados e Discussões}

Com esse experimento foi possível observar a longevidade das rosas var. "Grand gala” produzidas no município de Gravatá-PE. As avaliações permitiram acompanhar as 
etapas de senescência, da colheita ao descarte das hastes florais.

O tratamento T1 apresentou o maior número de hastes florais, com pontuação três, na terceira avaliação. Já o T2, apresentou apenas seis hastes florais na terceira avaliação, todas com pontuação 2. No T3 foi observado sete hastes na terceira avaliação, com apenas uma haste com a pontuação 3. Segundo Moraes et al. (1999) a sacarose tende a reduzir o potencial osmótico das pétalas e auxiliar no fechamento estomatal, melhorando a capacidade de absorção de água e favorecendo a manutenção da turgidez e o balanço hídrico destas. Já, Terral (2015) informa que o açúcar contido na água, além de evitar o crescimento de fungos, algas e bactérias, hidrata a haste floral.

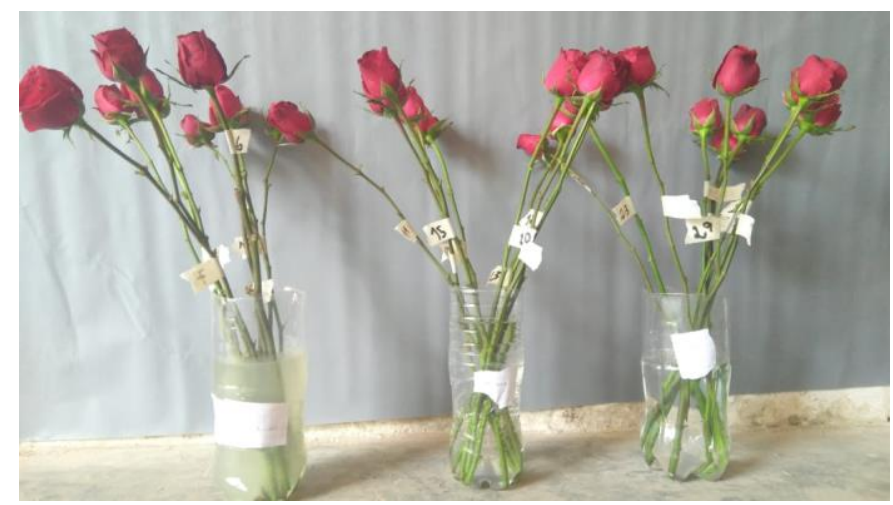

Figura 1. - Rosas variedade "Grand gala" avaliação de durabilidade, Vitória de Santo Antão -PE.

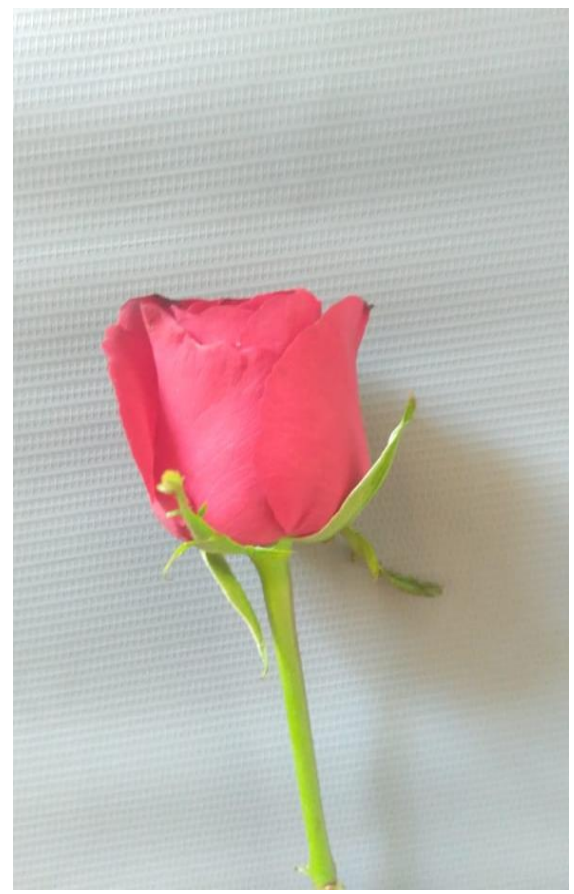

Figura2. - Rosa variedade "Grand gala" avaliação de durabilidade, Vitória de Santo Antão. 


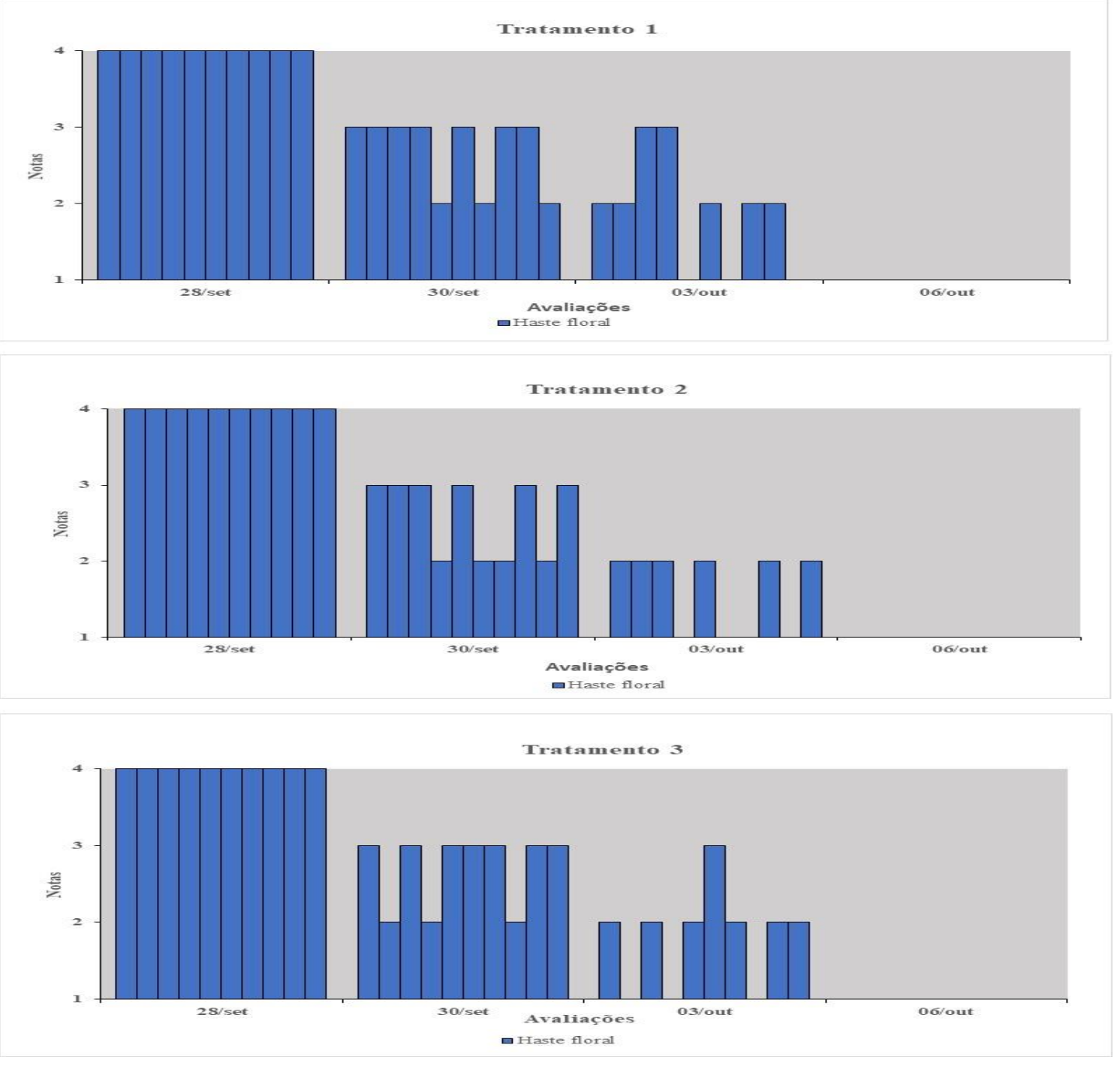

Figura 3. Durabilidades de hastes florais (rosas variedade Grand gala) no período de setembro a outubro de 2018, Vitória de Santo Antão-PE.

\section{Conclusões}

O tratamento com melhor durabilidade pós-colheita foi o T1 e T3, é recomendado que o experimento seja repetido com o maior número de hastes florais e que venha utilizar outras soluções caseiras.

\section{Referências}

ALMEIDA, E. F. A.; PAIVA, P. D. O; LIMA, L. C. O.; SILVA, F. C.; RESENDE, M. L.; NOGUEIRA, D. A.; PAIVA, R. Diferentes conservantes comerciais e condições de armazenamento na pós-colheita de rosas. Revista Ceres, Viçosa, v. 56, n. 2, p. 193- 198, 2009.

FINGER, F. L.; CARNEIRO, T. F.; BARBOSA, J. G.; Senescência pós-colheita de inflorescências de esporinha (Consolida ajacis); Pesq. agropec. bras., Brasília, v.39, n.6, p.533-537, jun. 2004 
IBRAFLOR - INSTITUTO BRASILEIRO DE FLORICULTURA. 2015. Dados do setor Condensado. Disponível em: <http://www.ibraflor.com/ns_mer_interno/php/2015/09/dadosdo-setor-condensado.> Acesso em: 28 out. 2018.

IBRAFLOR - INSTITUTO BRASILEIRO DE FLORICULTURA. 2017, 04 de NOVEMBRO. Mercado de flores prevê crescimento médio de $9 \%$ no Brasil e faturamento de R\$ 7 bi, em 2017. Disponível em <http://www.ibraflor/2017/11.com> Acesso em: 26 de out. de 2018

LANDGRAF, PAULO ROBERTO CORREA, Área de produção de flores de corte no Estado de Minas Gerais (16 $6^{\circ}$ Congresso Brasileiro de Floricultura e Plantas Ornamentais / $3^{\circ}$ Congresso Brasileiro de Cultura de Tecidos de Plantas / $1^{\circ}$ Simpósio de Plantas Ornamentais Nativas) 2009.

MORAES, P. J. de et al. Efeito da refrigeração e do condicionamento em sacarose sobre a longevidade de inflorescências de Strelitzia regina e Ait. Revista Brasileira Horticultura Ornamental, Campinas, v. 5, n. 5, p. 151-156, 1999.

PIETRO J; MATTIUZ BH; MATTIUZ CFM; RODRIGUES TJD. 2012. Manutenção da qualidade de rosas cortadas cv. Vega em soluções conservantes. Horticultura Brasileira 30: 64-70.

PLANTAS ORNAMENTAIS ASPECTOS PARA A PRODUÇÃO Disponível em: $<$ https://www.researchgate.net/profile/Claudia_Petry/publication/314420135_Plantas_Ornam entais_Aspectos_para_a_producao_2ed/links/58c1e784a6fdcce648daa3a3/2008/23PlantasOrnamentais-Aspectos-para-a-producao-2ed.pdf> Acessado em: 15 de Out. de 2018.

REID M (2004) ROSE, SPRAY ROSE, SWEETHEART ROSE: RECOMMENDATIONS FOR MAINTAINING POSTHARVEST QUALITY. POSTHAVETS TECHNOLOGY AND INFORMATION CENTER. University of California. Disponível em: $<$ http://postharvest.ucdavis.edu/produce/producefacts/orn/roses.pdf $>$ Acessado em: 20 de outubro de 2018.

REIS, S. N.; Soluções de pulsing e de manutenção pós-colheita de flores de corte; - Lavras: UFLA, 2009. 73 p. : il.

SANTOS, V. R.; Efeito da temperatura e inibidores da ação de etileno na longevidade póscolheita de flores esporinha (Consolida ajacis Nieulw) 14 de abril 2003.

SONEGO, G.; BRACKMANN, A. Conservação pós-colheita de flores. Ciência Rural, Santa Maria, v. 25, n. 3, p. 473-479, 1995.

\footnotetext{
TERRAL - CONSERVAÇÃO DE ROSAS - 05 DICAS PARA MANTER SEU BUQUÊ DE ROSAS LINDO POR MAIS TEMPO. 2015. Disponível em: $<$ http://terral.agr.br/plus/modulos/noticias/2015/terral-conservação-de-rosas-05-dicas-paramanter-seu-buquê-de-rosas-lindo-por-mais-tempo/ler.php?cdnoticia=14> Acesso em: 9 de Março de 2018.
} 